\title{
Jovens produzindo identidades sexuais ${ }^{*}$
}

Debbie Epstein

Cardiff University, School of Social Sciences

Richard Johnson

Nottingham Trent University, Faculty of Humanities

Tradução: Lene Belon

Revisão técnica: Guacira Lopes Louro

\section{Introdução}

Como podemos entender o modo como jovens formam suas identidades, particularmente em relação à sexualidade e ao gênero? Essa questão está no centro deste artigo, baseado em trabalho que realizamos, juntos e independentemente, ao longo dos últimos 17 anos, desde que começamos a trabalhar com questões da sexualidade.

A próxima seção do artigo apresenta descrições de seis jovens, personagens exemplares encontrados no trabalho de campo no decorrer de vários anos e em diferentes projetos no Reino Unido. Esse é o ponto de partida para a exploração da formação das identidades de jovens. Na segunda seção, argumentamos que os jovens se produzem como atores generificados e sexualizados bem como atores de raça e classe, em e através de certas relações centrais. Seus contextos mais imediatos, ao menos no Reino Unido, são as

\footnotetext{
* Versão preliminar deste artigo foi apresentada por Debbie Epstein no 30ª Reunião Anual da ANPEd, realizada em outubro de 2007, em Caxambu (MG).
}

culturas sexuais dos próprios jovens, formadas em relação a espaços institucionais, como as escolas, a cultura popular comercial e as relações domésticas e familiares. A terceira seção argumenta que as identidades são poderosamente formadas através do que Connell (1995, p. 62-64) chamou de "práticas reflexivas do corpo" - ou seja, o circuito de efeitos entre experiências corporais, vida emocional e explicações culturais para eles (Figura 1). É importante observar, no entanto, que esses entendimentos e experiências são desenvolvidos no contexto de relações sociais de poder em outros circuitos de produção cultural. Diferenças sexuais, por exemplo, estão sempre acompanhadas e são mutuamente moldadas por outras "diferenças que fazem diferença” na vida cotidiana das pessoas (como raça, gênero ou corporificação). Interações imediatas, face a face, estão sempre imbuídas de formações culturais mais amplas em torno do sexual (ou de outras diferenças sociais), que são reproduzidas e às vezes modificadas em práticas como representação na mídia, processos políticos e legais, venda e consumo de bens, conhecimentos científicos, profissionais e especializados. 
A seção final do artigo considera as implicações que tais entendimentos podem ter para práticas profissionais. Elas indicam que os praticantes, por exemplo, de profissões de cuidado, ensino ou assistência médica estão direta e ativamente envolvidos na construção da identidade de seus jovens clientes, alunos ou pacientes ao mesmo tempo em que constroem suas próprias identidades profissionais. Sugerimos que o poder do profissional não é só ouvir, prescrever, ensinar ou avaliar; é mais organicamente produtivo do que isso. A boa prática, então, envolve o reconhecimento ativo de diferenças na posição social, incluindo sexualidades, raça, etnia e classe. Argumentamos que a prática ética com jovens em relação às suas identidades emergentes somente é realizável quando os profissionais são autoreflexivos no que diz respeito às limitações de seus próprios horizontes e estão cientes de sua parcialidade.

\section{Seis jovens em busca de identidades}

Esta seção apresenta os seis indivíduos jovens que escolhemos, a partir do trabalho de campo de Debbie Epstein, como exemplos dos complexos processos de trabalho e formação de identidade em que todos os jovens com quem trabalhamos estiveram envolvidos. Esses personagens são jovens cujas identidades estão, de diferentes modos, sob pressão e que, portanto, mostram mais claramente as negociações, limitações e performances em que eles estão envolvidos.

\section{Tracy}

Tracy era uma jovem branca da classe trabalhadora, aluna de uma escola secundária profissionalizante, exclusiva para moças, de West Midlands. Tinha uma relação algo infeliz com a escolarização e estava em uma das turmas mais fracas do $10^{\circ}$ ano (14/15 anos). Faltava às aulas com frequência, aparentemente com consentimento dos pais. Ela era ponto de muito interesse e fofoca, tanto entre os professores quanto entre as outras alunas, porque se apresentava como interessada e experiente em sexo e, de fato, como sexualmente ativa. Falava sobre seus relacionamentos com ho- mens jovens (e também mais velhos), carregava um preservativo e o mostrava com floreios nas aulas de educação sexual. Ela insistia em usar maquiagem nos dias em que ia à escola, apesar de repetidas proibições. Os professores (e talvez os profissionais da saúde) percebiam-na como estando em risco de gravidez precoce. Em discussões comigo, Tracy expressou ter prazer e desconforto simultâneos com sua reputação e imagem pública e dava a impressão de ser muito menos envolvida sexualmente do que sua reputação ou autoapresentação poderiam sugerir. Ela produziu uma feminilidade performativa em que todos os diferentes aspectos de sua identidade social (classe, raça, gênero e sexo) desempenhavam seu papel. Trata-se de uma versão de jovem mulher heterossexual que tem sido submetida a uma sátira cruel na comédia de televisão do Reino Unido chamada Little Britain.

\section{Simon}

Simon era um jovem gay branco de classe média, aluno de uma escola secundária de Londres. ${ }^{1}$ Era alto, bem formado e muito atlético. Era capitão da equipe de rúgbi da escola. Tinha um namorado na mesma escola, que também estava na mesma equipe; eles andavam juntos, muitas vezes de mãos dadas e, em suas próprias palavras, "completamente expostos". Nem ele nem seu namorado, Peter, passaram pela experiência de intimidação homofóbica, mas sabiam que isso só era impedido por seu tamanho óbvio, porte atlético e, como Simon apontou, sua suposta heterossexualidade. Em outras palavras, ele e Peter

${ }^{1}$ As escolas secundárias fazem parte do antigo sistema tripartido do Reino Unido, em que os alunos eram selecionados para frequentar escolas secundárias (acadêmicas), técnicas e secundárias modernas (não-acadêmicas), com base em resultados de testes realizados com jovens de 11 anos. As escolas técnicas e secundárias modernas desapareceram, sendo substituídas por escolas secundárias profissionalizantes. No entanto, a existência de escolas secundárias que selecionam estudantes academicamente competentes em algumas áreas continua a distorcer a variação de habilidades nas escolas secundárias profissionalizantes locais. 
estavam completamente "expostos”, mas ninguém os via como qualquer outra coisa que não "bons amigos" ou colegas. Sabia que havia o perigo de tornar-se alvo de homofobia, e uma de suas estratégias de evitação era participar da intimidação de rapazes mais fracos e “efeminados” na escola. A autoapresentação de Simon era como ultramasculino, confiante, bem arrumado e “homogêneo". Sua estatura e o evidente porte atlético confirmavam tanto sua masculinidade quanto (equivocadamente) sua suposta heterossexualidade. Ele desfrutava de muito capital social, advindo de sua classe, da escola que frequentava e de seu sucesso educacional e esportivo. Era virtualmente uma versão didática de masculinidade - a masculinidade que se supõe ser desejável -, a não ser pelo fato de ser gay.

\section{Elias e Levi}

Elias era um menino turco da classe trabalhadora, um "pré-adolescente" em uma escola de Londres. Era muito atraente, tanto em termos de personalidade quanto de aparência. Era o menino mais popular na sua série entre meninos e meninas. No entanto, conseguia ser um tanto problemático (e, portanto, menos atraente) para os professores e tinha dificuldade de manter um padrão aceitável nas tarefas escolares. Elias passava a maior parte do tempo com seu melhor amigo, Levi, um menino afro-caribenho quase tão atraente quanto ele. Ambos eram tidos como "namorados" e sabiam-se como tal. Já consideravam sua atratividade heterossexual como certa, mas estavam mais envolvidos emocionalmente um com o outro (e com Arsenal) do que com qualquer outra de suas supostas "namoradas", com quem passavam pouco tempo. Elias e Levi, de vez em quando, envolviam-se no assédio sexual de meninas (as mesmas que gostavam deles). As garotas pareciam achar isso simultaneamente exasperador, ameaçador e excitante o que só aumentava a atratividade dos meninos, em vez de diminuí-la, embora as meninas também relatassem considerar muito incômodas as invasões dos meninos nos vestiários durante as aulas de natação. As versões de masculinidade apresentadas por esses meninos demonstravam muitas nuances de etnicidade no estilo de vestir, corporificação e comportamento. Levi, por exemplo, obviamente passava muitas horas raspando a cabeça com precisão, fazendo os devidos desenhos, e caminhava com o ar arrogante que costuma ser exibido por jovens afro-caribenhos mais velhos em Londres. A autoapresentação de Elias era um pouco menos arrogante, mas, com Levi, ele certamente conseguiria andar do modo desejável.

$$
\text { Morgan }
$$

Morgan era uma menina branca de classe média que estudava numa escola mista; ela escolheu esse pseudônimo a partir da versão feminista da lenda de Arthur, denominando-se Morgan le Fey, a irmã malvada nas versões dominantes mas aliada às boas e antigas religiões originais em algumas versões feministas. Estava nos primeiros anos da adolescência e era a garota mais popular de sua série, especialmente entre as meninas. Havia tido um namorado, Michael, desde a $5^{\mathrm{a}}$ série (1011 anos), seu "amor de infância". Ela estava no controle de todos os seus relacionamentos. Quando Morgan era bem mais nova, eu havia observado como ela já liderava as outras crianças (meninos e meninas) em brincadeiras que eram tanto familiares quanto sexualizadas no sentido mais amplo (descrito em detalhes em Epstein et al., 2001). Morgan jogava futebol muito bem, e isso era fonte de parte de sua popularidade; ela também estava envolvida em uma espécie de versão do "poder das meninas”, derivada das Spice Girls quando elas eram populares, mas levada além na vida cotidiana de Morgan na escola. Morgan era uma grande realizadora, era assertiva e tinha boas relações com adultos e crianças.

\section{Lara}

Lara era de origem punjabi e identificava-se como lésbica. Ela procedia assim desde meados da adolescência e, naquela época, acreditava ser a única lésbica asiática no mundo. Esta era sua própria descrição:

Eu achava que era a única lésbica asiática do mundo. Eu era $a$ lésbica asiática e fui posta na Terra para começar essa 
revolução entre lésbicas asiáticas, para..., sobre ser gay. E esse era meu propósito na vida. [...] E, sabe, minha imagem de lesbianismo era cabelo curto, uma verdadeira sapatão branca de cabelo bem curto, com botas de estilo militar, e aqui estava eu, esta mulherzinha punjabi, esta menina punjabi que, sabe, adorava brincos longos e cabelos compridos... eu adorava roupas asiáticas.

A autoapresentação de Lara estava muito marcada tanto em seu gênero quanto em sua etnicidade. Suas palavras autodescritivas mostram o quão importantes ambos os aspectos eram para ela.

\section{Identidade como autoprodução/agência}

Diríamos que os jovens se produzem como atores generificados e sexualizados em e através de certos relacionamentos principais. Seus contextos mais imediatos são suas próprias culturas sexuais, formadas em relação a espaços institucionais, como as escolas, a cultura popular comercial e as relações domésticas e familiares. Nesse contexto, faz sentido pensar em questões de saúde, bem-estar e autoimagem de jovens como entrelaçadas com questões de identidade e com o cuidado e a produção do eu. Entendemos identidade aqui não como algo dado pela anatomia ou por genes, nem mesmo como desenvolvimento psicossocial, mas como algo produzido por trabalho árduo e performance ativa. É algo construído em muitos níveis diferentes. Tanto o interpessoal quanto o intrapessoal desempenham seu papel como constantes reiterações de práticas performativas que, como Judith Butler sugere $(1990,1993)$, vêm a ser escritas no corpo. Essas performances iterativas nunca são exatamente umas como as outras e são de natureza relacional. Podem ser vistas como chave na produção do eu. Claro que essa autoprodução ocorre em condições que os jovens não controlam. Eles não são os criadores livres das capacidades e limites de seus corpos. Geralmente não inventam de forma completamente nova as histórias com que narram suas vidas. Não produzem os bens que utilizam para criar um estilo. Estão emergindo da impotência relativa da infância para um mundo adulto já desigualmente estruturado, mas tampouco recebem passivamente a marca de seu ambiente cultural e social; não são meros receptores de informações úteis ou do aconselhamento adulto racional.

Tomaríamos como axiomático que fazer a si mesmo, fazer sua identidade, envolve suas relações com os outros ${ }^{2}$ - quem você quer ser, com quem você quer estar, com quem quer se parecer, quem quer que goste de você, mas também de quem quer ser diferente, de quem não quer gostar, quem lhe causa repulsa, quem é seu "outro". Ambos os lados dos pares amor/ ódio, desejo/repulsa são importantes nesse contexto. A produção da identidade é um processo intra e interpessoal em que quem se é (ou está se tornando) deriva de uma combinação de como se vê o seu "eu”, suas histórias pessoais e suas relações com os outros. Aqui, estamos falando de todos os tipos de outros significativos na vida de uma pessoa. Pais, irmãos e a experiência precoce de ser cuidado (ou não) são importantes, mas não a única fonte de produção de identidade. Outros “outros” também estão envolvidos, sejam eles “colegas”, “amigos” e “inimigos”, amantes, ídolos, figuras de ódio ou modelos e antimodelos. No contexto da escola, esses outros provavelmente são outros alunos ou professores; além deles, há astros e estrelas pop e outras celebridades cujo lugar na imaginação resulta de uma negociação entre o trabalho que tais pessoas fazem para construir suas próprias imagens e a multiplicidade de modos como são lidas. A produção de identidade é relacional, tanto no nível da fantasia quanto nas interações cotidianas com outros, inclusive - e, de forma importante, - com os pares.

Nossos personagens exemplares ilustram muitas das práticas por meio das quais os jovens se produzem. Como já mostramos em outro lugar (Epstein et al., 2001), as repetições prazerosas de brincadeiras por Morgan, seu namorado Michael e seus amigos e suas amigas em jogos imaginativos envolviam não somente mamães, papais e bebês, mas também trabalhadores sociais e médicos. Simon e Peter também se produziam

\footnotetext{
${ }^{2}$ Para uma discussão sobre intersubjetividade em relação
} às formações do eu e da psique, ver Stolorow e Atwood (1992). 
em um tipo diferente de brincadeira - rúgbi -, que era reconhecida e regulada por regras de esporte em equipe e códigos culturais de masculinidade. A constituição de um estilo pessoal já estava sendo treinada por Elias e Levi, que certamente vestiam o que era vestido, trilhavam o caminho trilhado e falavam o que era falado por rapazes mais velhos que eles admiravam, ao passo que a explicitação heterossexual de Tracy envolvia maquiagem e roupas, especialmente a adaptação do uniforme da escola, para torná-la sexy. Lara, em contrapartida, estava lutando para encontrar um estilo, não satisfeita nem com a imagem de "sapatão" de cabelo curto que ela percebia como lésbica na branquitude nem com a de mulher asiática heterossexual convencional (apesar de seu gosto por roupas femininas tradicionais). Ela teve que se produzir como única na medida em que prosseguia a única lésbica asiática no mundo.

Há duas qualificações importantes do argumento desenvolvido até aqui. Primeiro, embora com frequência encontremo-nos admirando a capacidade de recursos dos jovens, não queremos apresentar uma visão simples e heroica de sua autoprodução. Os processos de formação de identidade estão cheios de ambivalência e contradição. Uma das estratégias de Tracy, por exemplo, era importar uma sexualidade adulta conhecedora para o contexto oficialmente dessexualizado da escola. Ela entendia que isso lhe dava certo status, até mesmo proeminência, mas também pagava um pesado preço em termos de reputação por sua imagem de "garota má", como discutimos em Schooling Sexualities (Epstein \& Johnson, 1998). Seria essa uma estratégia de identidade que poderia ser satisfatoriamente sustentada e que ajudaria Tracy a desenvolver um senso de satisfação e bem-estar em sua vida? Ao representar a menina "má” ou "sexy", Tracy poderia estar se defendendo de situações causadoras de ansiedade. Por exemplo, ela estava sendo estouvada e "difícil” e rejeitando valores da escola a fim de se resguardar da rejeição? Fazer perguntas como essa sobre as ações de jovens em relação a situações escolares ou familiares pode não levar a respostas, mas pode dar uma pausa na irritação e na raiva sentidas pelos professores.
Segundo, estamos longe de argumentar que a agência dos jovens sempre produz bons resultados para eles mesmos e para os outros. Está claro, por exemplo, que as estratégias empreendidas por Tracy, Elias e Levi podiam trazer-lhes destinos específicos de classe subordinada como menina e meninos academicamente "fracassados". Levi, por exemplo, como menino afro-caribenho nos meados e no final da adolescência, parecia ter muita probabilidade de atrair atenções racistas da polícia - e parecia muito provável que tanto ele quanto Elias fossem parar no lado oposto da lei. Além disso, esses meninos poderiam representar um problema para as meninas, com suas invasões dos vestiários das piscinas, por exemplo.

\section{Práticas reflexivas do corpo}

Argumentando que jovens se produzem de modos culturais, não estamos sugerindo que o corpo, como em algum sentido dado, não é importante. Bob Connell (1995), em seu livro Masculinities, propõe a ideia de práticas reflexivas do corpo. Pensando sobre essa noção, desenvolvemos uma representação das ideias de Connell em forma de diagrama, com base na noção de Johnson (1986) do circuito da cultura (Figura 1).

Figura 1: Circuito de produção como práticas reflexivas corporais

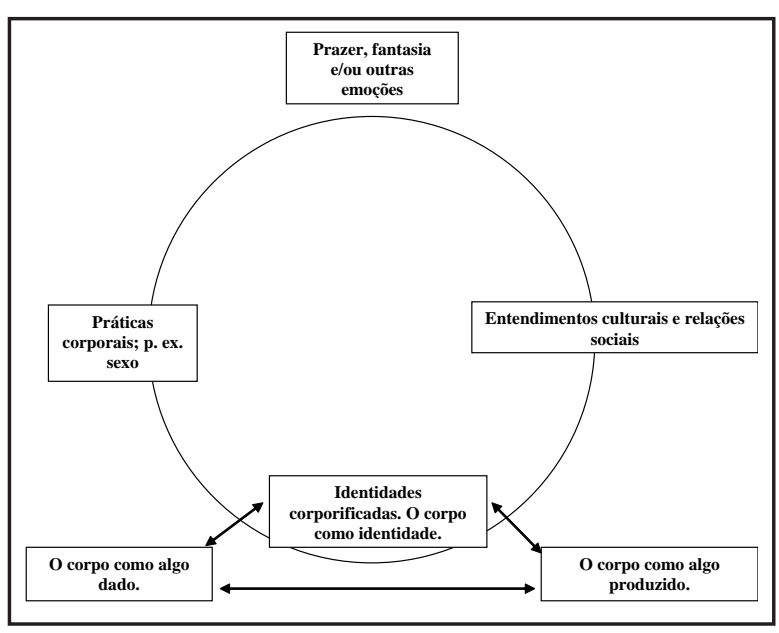

Podemos começar em qualquer ponto específico da Figura 1. Se tomarmos o caso de Simon e seu amigo 
Peter e partirmos de experiências corporais, veremos que eles eram namorados ativos quando estavam na escola. Sua experiência como jogadores de rúgbi no time da escola e suas práticas homossexuais eram compreendidas e interpretadas por eles através de meios culturais. Eles compartilhavam versões específicas de prazer corporal - no sexo e na boa forma física-, produzindo-se como desejados e desejáveis de modos específicos. Eles trabalhavam em seus corpos (que eram considerados grandes e aptos para a prática de esporte) para produzirem-se como atléticos, fortes e habilidosos em maneiras muito específicas para o jogo bem-sucedido de rúgbi. Mas, para isso acontecer, deveria haver práticas socialmente disponíveis (no seu caso, o jogo de rúgbi) que oferecessem pontos de reconhecimento para meninos grandes, fortes, gays - em uma cultura esportiva que é infamemente homofóbica, misógina e, ao mesmo tempo, homoerótica. E assim voltamos ao corpo. Os meninos tinham os corpos grandes necessários para o sucesso no rúgbi e talvez tendência inata para boa coordenação corporal, mas desenvolveram essas capacidades mediante prática e treinamento, o que envolveu o trabalho em seus corpos e em suas identidades corporificadas.

Se tomarmos o exemplo da gravidez potencial (e prevista) de Tracy na adolescência, poderemos ver que isso seria uma transformação e criação muito ativa do corpo. Como professores, profissionais da saúde e elaboradores de políticas, podemos ver as desvantagens da gravidez adolescente, tanto para as mães quanto para os bebês - a interrupção da educação e o risco de pobreza, por exemplo. É importante reconhecer também que a gravidez pode ser - e com frequência é - uma estratégia com sua própria racionalidade, uma estratégia que confere à menina a condição de adulta e relacionamento emocional, bem como trabalho, preocupação, despesas e prejuízo à sua educação (Bullen, Kenway \& Hey, 2000; Aldred \& Davids, 2007). É por isso que a ideia (muito popular entre os elaboradores de políticas e alguns educadores no Reino Unido) de dar às jovens mulheres uma boneca que chora e precisa ser alimentada como forma de desencorajá-las a ficar grávidas (ou de os rapazes engravidarem alguém) é uma quimera. Winnicott (1965) chamou a intensa preocupação que as mães geralmente têm com seus bebês de "preocupação maternal primária”. Ele diz:

\begin{abstract}
A questão é que, no final da gravidez e durante algumas semanas após o nascimento da criança, a mãe fica preocupada com (ou melhor, “dedicada ao”) cuidado do bebê, que, primeiramente, parece ser parte dela mesma; além disso, ela se identifica muito com o bebê e sabe muito bem como ele está se sentindo. Por isso, ela usa suas próprias experiências como bebê. Desse modo, a mãe está, ela mesma, em um estado dependente e vulnerável. (p. 85)
\end{abstract}

Entretanto, as jovens mulheres não têm o imperativo biológico da gravidez, do parto e dos hormônios que os acompanham nem a conexão emocional com as bonecas. As bonecas não retribuem amor, não dependem da mãe, não reagem emocionalmente, não sorriem, não abraçam, não agarram nem fazem todas as outras coisas que um bebê faz para envolver a mãe e outros adultos na própria produção infantil de si mesmo, isso para não falar na resposta da mãe ao bebê. A boneca, por mais realista que seja, não propicia nada ao circuito reflexivo do corpo para envolver as jovens mulheres; a experiência corporificada, a expectativa cultural e os investimentos psíquicos e emocionais que a maioria das mulheres faz em seus filhos estão todos ausentes.

\section{Contextos, condições sociais}

Quando jovens dão significado às suas vidas, usam narrativas e imagens que já foram produzidas em outro lugar. Por exemplo, a escolha de Morgan de seu pseudônimo baseou-se na versão feminista (que lhe foi contada por sua mãe) da lenda de Arthur. Igualmente, o nome de Elias (e parte de sua reputação) surgiu de sua repetida inserção em rimas nas brincadeiras de pular e bater palmas realizadas no pátio por meninas do seu grupo e de outras turmas. Lara, por sua vez, usava e apreciava as roupas tradicionais, apesar de não querer ocupar a posição feminina tradicional em sua cultura. Um modo de compreender os papéis de quem trabalha 
com jovens e dos produtores de conhecimento é que eles operam (assim como nós operamos) como outra fonte de identidades e narrativas culturais para os jovens. Isso se dá através da gama de profissões públicas. Por exemplo, Valerie Harwood discute como o rótulo “condutor de desordem" afeta as maneiras como os jovens com tal diagnóstico veem a si mesmos. Ela sugere que a psiquiatria, como conhecimento e prática, coloca pressão sobre os clientes para que estes se produzam como sujeitos psiquiátricos, isto é, como mentalmente desordenados. De forma semelhante, professores e profissionais que trabalham com jovens estão necessariamente envolvidos no processo de sua produção de identidade de modos que são respaldados por formas particulares de poder, desde a avaliação acadêmica até a segmentação psiquiátrica. Podemos ampliar o quadro aqui e insistir que os jovens se produzem com identidades reconhecidas socialmente já correntes na cultura mais ampla. Há sempre uma apropriação individual, uma inflexão biográfica, mas o trabalho de identidade é sempre duplamente pressionado: primeiro, a partir do nível dos recursos materiais e corporais; segundo, a partir dos roteiros mais insistentes ou dominantes. Em relações sexuais, por exemplo, a pressuposição de heterossexualidade sempre torna mais difícil, para os gays e as lésbicas, buscar aconselhamento apropriado sobre temas sexuais e outros.

Na Figura 2, apresentamos um circuito mais abrangente de produção, que denominamos circuito de produção de identidade. A corporificação, que vimos anteriormente como um circuito, é parte desse quadro mais amplo, mas somente parte dele. Em cada ponto desse circuito, podemos identificar uma gama de relações de poder e desigualdades em relação aos recursos, às possibilidades de reconhecimento, à sustentabilidade de estratégias de identidade disponíveis para pessoas em diferentes posições sociais. Se começarmos no topo do circuito, será possível distinguir aquelas identidades que são mais prontamente reconhecidas socialmente - e estas variam com o tempo e o lugar. A introdução da instituição de "parcerias civis" no Reino Unido pode ter o efeito de tornar relacionamentos não-heterossexuais mais facilmente reconhecíveis e socialmente aceitáveis. Entretanto, isso não significa que sejam socialmente aceitáveis em escolas para que jovens também se identifiquem, de algum modo, como queer. Ao contrário, a economia sexual das escolas (Hey, 1997) é tal que a pressuposição de heterossexualidade continua a ser forte e pode ser muito difícil para jovens, em especial para os meninos, agarrar-se a tais identidades com alguma convicção, segurança ou autoestima.

Figura 2: Circuito de produção de identidade

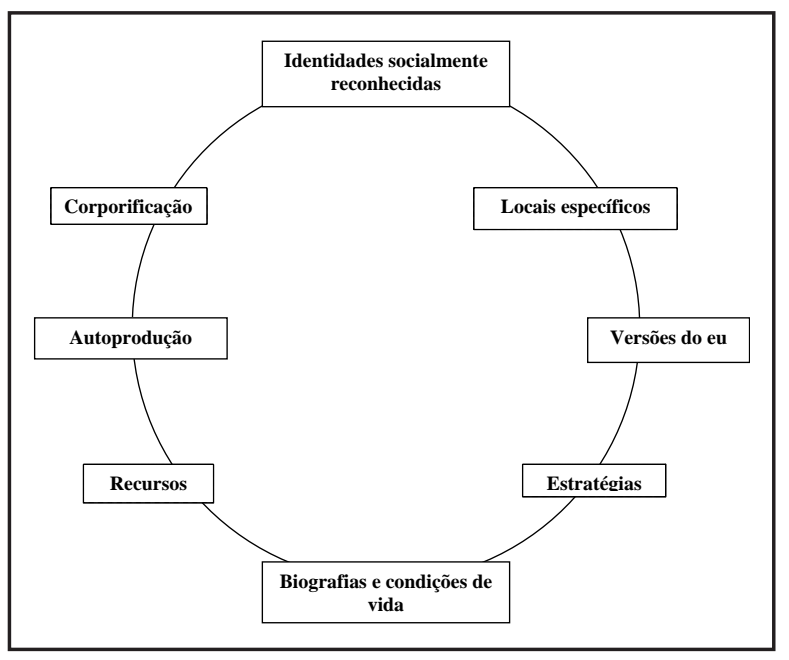

De forma parecida, O’Flynn e Epstein (2005) mostram como pouco reconhecimento social é dirigido para estudantes refugiados no Reino Unido com famílias não normativamente heterossexuais. Esses/ as estudantes têm dificuldade de "expor" sua organização familiar na escola, seja para outros estudantes, seja para a escola oficial (por exemplo, dizer como seu parente mais próximo é denominado quando o casamento é polígamo). Eve Sedgwick (1990) argumenta que a metáfora do "armário" é a metáfora da idade - e que todos nós sabemos que o “armário” existe e que ele representa um grande papel na produção e sustentação da heterossexualidade, assim como faz no encobrimento da homossexualidade, e o trabalho de Sarah O’Flynn (2007) demonstra isso de maneira admirável. Se prosseguirmos ao longo do circuito, por meio de estratégias e locais específicos para versões do eu que jovens podem sustentar, desenvolver, nutrir ou rejeitar e para suas biografias pessoais e condições de 
vida - o que os domínios da possibilidade são para eles nos processos de autoprodução e contextos de relações de poder em que ocorrem -, poderemos ver que cada ponto do circuito apresenta diferentes complicações e dificuldades potenciais.

Nesse contexto, é impossível separar, de alguma maneira sensata, gênero de sexualidade ou viceversa. Gênero é desempenhado pela sexualidade, e a sexualidade, por meio do gênero. Igualmente, em sociedades racializadas e organizadas por classes, raça/ etnia também são sempre generificadas, sexualizadas e afetadas pela classe - daí a importância de observar não apenas o gênero dos personagens trazidos como exemplos como também sua raça, sexualidade e classe. Um não existe sem o outro, e cada um é desempenhado pelo outro (ver também Nayak, 1999).

Mais um ponto antes de passarmos para algumas implicações práticas desta análise: devido à relação próxima entre crescer no sentido cultural e o amplo campo cultural, as contradições nesse campo causam uma pressão particularmente forte sobre jovens. A sexualidade é um bom exemplo aqui. Como todos nós sabemos, há marcadas tendências em direção à crise nas formas mais aprovadas de relações íntimas e sexuais, especialmente na instituição do casamento e nas formas mais conhecidas de relações de gênero. Uma das maneiras como a crise tem sido tratada nos últimos 20 ou 30 anos é a insistência no casamento como peça central para a educação sexual, uma prática cada vez mais detidamente regulada - e isso é certamente o caso no Sex and Relationship Education Guidance (DfEE, 2000) do governo do Reino Unido. Professores e crianças são frequentemente culpados por um movimento social muito mais amplo, que produziu e continua a produzir uma enorme diversidade de maneiras de vivência sexual que têm sua própria legitimidade.

Ao mesmo tempo, como Haskey (1998, p. 32-33) observa, nunca antes as pessoas viveram em tantos tipos diferentes de família. Por exemplo, há 15 anos, o General Household Survey 1991 relatou que, embora um pouco mais de dois terços de crianças com menos de 16 anos estivessem vivendo com o pai e a mãe biológicos, nem todos os casais eram casados. Além disso, entre 1981 e 1991, a proporção de crianças que viviam em famílias com apenas a mãe passou de 8 para $17 \%$ entre as crianças abaixo de 4 anos, de 9 para $19 \%$ entre crianças de 5 a 9 anos e aumentou 50\% para as de 10 a 15 anos (OPCS, 1993). Essa é uma tendência em andamento, e Gingerbread ${ }^{3}$ (1998) estima que entre um terço e a metade da próxima geração passará mais tempo em famílias com apenas um dos genitores. O número de crianças dessas idades que têm padrasto ou madrasta também aumentou drasticamente no período, com alta taxa de recasamento após o divórcio (Newman \& Smith, 1997). O relatório da Social Exclusion Unit sobre Teenage Pregnancy (1999) relatou que 56 mil mulheres jovens abaixo dos 20 anos (de 90 mil concepções) dão à luz no Reino Unido por ano, incluindo 8 mil com menos de 16 anos de idade. Como mostra esse relatório, é provável que essas jovens vivam com seus filhos em famílias de um só genitor ou em famílias multigeracionais, mas é menos provável que vivam com seu parceiro e a criança ou em um casamento legal. A incidência de divórcio e de recasamento significa que muitas outras crianças estão vivendo em famílias com padrões complicados de padrastos ou madrastas e meio-irmãos e passando tempo com cada um dos pais em diferentes residências. Igualmente, o crescimento na prevalência de pais ou mães de mesmo sexo significa que há jovens em muitas escolas que, embora se identifiquem como heterossexuais, têm pais gays ou mães lésbicas. Consequentemente, não faz sentido educar as crianças como se a parceria monogâmica e heterossexual ainda fosse a única forma socialmente aprovada de vida sexual. Elas sabem que não é esse o caso, a partir de suas próprias experiências e das de seus amigos.

\section{Conclusão: implicações para a prática}

Chegando ao final de nossa argumentação, queremos enfatizar a importância absoluta de considerar o que poderia ser chamado "projetos de identidade" com que lidam professores e outros profissionais. Isso

\footnotetext{
${ }^{3}$ Instituição de caridade que dá apoio a mães e pais solteiros.
} 
não quer dizer simplesmente tentar compreender ou ter empatia com jovens, e sim fazer avaliações críticas, mas respeitosas, dos projetos particulares daqueles/as com quem estamos lidando. Se olharmos os exemplos que mencionamos, poderemos fazer algumas perguntas sobre nossos jovens.

Elias e Levi, por exemplo, são "meninos fracassados"; então, onde irão conseguir emprego, sustentar seu estilo de vida como homens jovens potencialmente bonitos, com gostos caros em termos de bens de consumo e sem meios de apoio financeiro? Para professores, um esforço prático deve ser trabalhar com eles para que desenvolvam seus próprios projetos de modo que sejam mais satisfatoriamente sustentáveis. Para trabalhadores da saúde, haverá outras preocupações relacionadas - por exemplo, em torno de questões como uso de álcool e violência entre meninos. De forma semelhante, como apontamos, a possibilidade de que Tracy se torne uma jovem mãe solteira tem implicações tanto para sua saúde quanto para sua educação. Mas abordá-la de modo que confirme sua infantilidade, que ela está tentando deixar para trás, não é respeitoso nem útil. Consequentemente, os professores precisam estar cientes de como suas práticas constroem possibilidades e espaços para a produção de identidade de jovens em contextos escolares e, nesse contexto, de como sua própria prática constrói identidade em relação ao sexual. Há na sociedade uma tendência de patologizar certas formas de identidade. Entretanto, a visão de que versões de sexualidade que não são tradicionalmente heterossexuais constituem alguma espécie de "condição" prestou-se, no passado, a práticas que a maioria das pessoas hoje rejeitaria como não-éticas - como tentar "curar" a homossexualidade, diferente de “disforia de gênero”. Mas, mesmo que agora não tentemos curar jovens gays, lésbicas e pessoas bissexuais, também não lhes oferecemos aconselhamento ou modelos disponíveis apropriados, sejam médicos, sociais ou educacionais.

Finalmente, alguns pontos sobre conhecimento, incluindo o status de nossos próprios conhecimentos, como praticantes e pesquisadores, e o de professores e outros profissionais. Acompanhamos grande parte do debate contemporâneo nas ciências humanas e sociais sobre a possibilidade de uma posição objetiva, própria de um deus, como produtores de conhecimento. Ao contrário, parcialidade é tudo o que temos. Todo conhecimento é produzido a partir de posições sociais específicas em relação aos outros que procuramos conhecer. Todo conhecimento trabalha com paradigmas específicos, com suas próprias percepções, limites e fechamentos. O conhecimento científico é somente um modo de conhecer, mas objetiva um tipo de domínio que constrói o outro como um objeto. Esse paradigma de conhecimento é tão dominante que, com frequência, desqualifica outras formas de saber.

Na verdade, as abordagens e métodos de uma investigação são sempre dependentes do que queremos saber. Se estamos preocupados com as culturas e identidades de jovens, temos que tratá-los como sujeitos e não objetos, qualificando nossos próprios preconceitos e poder mediante diálogo, bem como por meio de escuta e observação cuidadosas. Esse modelo de conhecimento como interpretação e compreensão que tenta atravessar grandes diferenças sociais tem que abrir seu caminho em uma cultura em que os jovens caracteristicamente não são ouvidos e são tratados como fontes de problemas e perigos, como vítimas ou ameaças, como portadores/as de patologias de diferentes tipos. Um dos objetivos deste artigo é pôr à prova as afinidades entre nosso tipo de compreensão de jovens e as maneiras éticas práticas de nos relacionarmos com eles, que consideram parcial a nossa visão do conhecimento. Ao pensarmos sobre os jovens que "preencheram" nossa pesquisa por um longo período de tempo, terminamos por reconhecer tanto seus recursos quanto as limitações sob as quais operam e onde suas identidades são (per)formadas.

\section{Referências bibliográficas}

ALDRED, Pam; DAVIDS, Miriam. Get real about sex: the politics and practice of sex education. Maidenhead: Open University Press, 2007.

BULLEN, Elizabeth; KENWAY, Jane; HEY, Valerie. New labour, social exclusion and educational risk management: the case of 
'gymslip mums'. British Educational Research Journal, v. 26, n. 4, p. 441-456, 2000.

BUTLER, Judith. Gender trouble: feminism and the subversion of identity. New York and London: Routledge, 1990.

Bodies that matter: on the discursive limits of sex'. New York and London: Routledge, 1993.

CONNELL, Robert W. Masculinities, Cambridge: Polity, 1995. DfEE - Department for Education and Employment. Sex and Relationship Education Guidance. Annesley: Nottingman, 2000. EPSTEIN, Debbie; JOHNSON, Richard. Schooling sexualities. Buckingham: Open University Press, 1998.

.; KEHILY, Mary J.; MAC AN GHAILL, Maírtin;

REDMAN, Peter. Girls and boys come out to play: making masculinities and femininities in primary playgrounds. Men and masculinities. Disciplining and punishing masculinities, v. 4, n. 2, p. 158-172, 2001.

GINGERBREAD. Lone parent families: action facts. London: Gingerbread, 1998.

HASKEY, John. Families: their historical context, and recent trends in the factors influencing their formation and dissolution. In: DAVID, Miriam (Ed.). The fragmenting family: does it matter. London: Institute of Economic Affairs, 1998.

HACHEY, Valery. The company she keeps: an ethnography of girls, friendships. Buckingham: Open University Press, 1997.

HEY, V. The company she keeps: an ethnography of girls, friendships. Buckingham: Open University Press, 1997.

JOHNSON, Richard. What is cultural studies anyway? Social Text, v. 16, p. 38-80, 1986.

NAYAK, Anoop. White English ethnicities: racism, anti-racism and student perspectives. Race Ethnicity and Education, v. 2, n. 2, p. 177-202, 1999.

NEWMAN, Peter; SMITH, Allan. Social focus on families. London: The Stationery Office, 1997.

O'FLYNN, Sarah. Testing times: the construction of girls' desires through secondary education. S.l: Cardiff University, 2007. (Unpublished $\mathrm{PhD}$ thesis.)

O’FLYNN, Sarah; EPSTEIN, Debbie. Standardising sexuality: embodied knowledge, achievement and standards. Social Semiotics, v. 15, n. 2, p. 183-208, 2005.

OLIVEIRA, Dora. Brazilian adolescent women talk about HIV/ AIDS risk: reconceptualizing risky sex - what implications for health promotion? Culture, communication and society. London: Institute of Education, University of London, 2000.
OPCS. General Household Survey 1991. London: Office for Population and Census Statistics, 1993.

SEDGWICK, Eve K. Epistemology of the closet. Berkeley: University of California Press, 1990.

SOCIAL EXCLUSION UNIT. Teenage Pregnancy. London: Social Exclusion Unit, 1999.

STOLOROW, Robert D.; ATWOOD, George E. Contexts of being: the intersubjective foundations of psychological life. Hillsdale: The Analytic Press, 1992.

WINNICOTT, Donald W. From dependence towards independence in the development of the individual. In: WINNICOTT, Donald W. The maturational processes and the facilitating environment. London and New York: Karnac Books, 1965.

DEBBIE EPSTEIN, PhD em sociologia pelo Departamento de Estudos Culturais da Birmingham University, é professora de educação na School of Social Sciences da Cardiff University e editora da revista Gender and Education, com Mary Jane Kehily e Emma Renold. Tem numerosas publicações sobre questões de gênero, sexualidade e “raça”/etnia nos campos da educação e da cultura popular, entre elas: Schooling sexualities, em coautoria com Richard Johnson, traduzido para o espanhol com o título de Sexualidades e institución escolar (Madrid: Morata, 1998) e Failing Boys? Issues in gender and achievement, organizado em conjunto com Jannette Elwood, Valerie Hey e Janet Maw, para o Centre for Research and Education on Gender, University of London, Institute of Education.E-mail: epsteind@cardiff.ac.uk

RICHARD JOHNSON, foi professor de estudos culturais na Nottingham Trent University e diretor do Center for Contemporary Cultural Studies da Birmingham University. Atualmente está aposentado e se dedica ao ativismo político por igualdade e justiça. Tem uma extensa publicação sobre teoria cultural, nação e outras questões de identidade cultural e social entre elas elas Schooling sexualities, em coautoria com Debbie Epstein, traduzido para o espanhol com o título de Sexualidades e institución escolar (Madrid: E. Morata, 1998) e "Sexual dissonances: or the ‘impossibiligy’ of sexuality education”, Curriculum Studies, v. 4, n. 2, 1996.

Recebido em agosto de 2008 Aprovado em novembro de 2008 